\title{
The Application of Cool Air from Thermoelectric for Reduce Temperature in Ozone Tube of Ozonizer Affecting to Ozone Gas Quantity
}

\author{
Siseerot Ketkaew \\ Faculty of Engineering, Ramkhamhaeng University, Bangkok, Thailand
}

\section{Email address:}

siseerot@hotmail.com

\section{To cite this article:}

Siseerot Ketkaew. The Application of Cool Air from Thermoelectric for Reduce Temperature in Ozone Tube of Ozonizer Affecting to Ozone Gas Quantity. International Journal of Science, Technology and Society. Vol. 5, No. 5, 2017, pp. 175-178. doi: 10.11648/j.ijsts.20170505.15

Received: July 26, 2017; Accepted: August 10, 2017; Published: September 19, 2017

\begin{abstract}
This research paper presents to the temperature reducing in ozone tube of ozonizer by applied thermoelectric for producing cool air. To observe the amount of ozone gas produced is ozonizer using inverter high voltage high frequency of half-bridge type at switching frequency $25 \mathrm{kHz}$ and controls its operation using pulse width modulation (PWM) technique and can produce high voltage at $3 \mathrm{kV}$ for supply to the ionizing bar at the highly non-uniform electric field ozone tube of two level insulator cylindrical, which in the first hour of the test machine can produce ozone gas at $216.8 \mathrm{mgO}_{3} / \mathrm{hr}$ of temperature is $29^{\circ} \mathrm{C}$. When researcher use cool air from thermoelectric to blow the bar of ozone, it can produce ozone at $379.5 \mathrm{mgO}_{3} / \mathrm{hr}$ of temperature at $25^{\circ} \mathrm{C}$. Thereby producing a cooling air by thermoelectric result in temperatures drop. As a result, the rate of decomposition of ozone gas gets lessening and can produce higher ozone gas. Therefore, future research will be designed to produce ozone gas from the cooling system thermoelectric to develop a real application for removal of odors from the food industry.
\end{abstract}

Keywords: Ozone Tube, Temperature, Ozonizer, Half-Bridge Converter, Thermoelectric, Cooling, High Voltage, High Frequency

\section{Introduction}

Ozone gas is widely brought to use for living such as using ozone to clean the vegetables instead of manganese to kill diseases and reduce a quantity of chlorine in water. Bringing ozone to clean the air purely has some drawbacks. For examples, if it is used too much concentrated, it can irritate to the body. It is useful to the health if quantity is properly used and is applied for work suitably. Therefore, to control the quantity of ozone gas should be matched with the work. This is the reason why to study and generate ozone gas. This paper presents a study of the effect of temperature decreasing at ozone tube using cool air from thermoelectric to the ozone gas quantity. The high voltage high frequency is constructed by using a principle of switching AC power supply. A high voltage high frequency is supplied to the load, which are two-layer electrode in series, for producing ozone gas. The generating ozone gas is based on the principle of spreading molecules of oxygen. It will produce ozone gas from the equation of $\mathrm{O}_{2}+\mathrm{O}=\mathrm{O}_{3}$. The ozone gas can withstand a high voltage level. Also, the heat affects to the quantity of the occurring ozone gas. Therefore, the quantity of voltage and the suitable frequency have to be controlled to generate ozone gas [1].

\section{Method}

\subsection{Diagram Block of Ozonizer Using Air Cooler}

Figure 1 shows the diagram block of ozonizer, which is constructed from the AC high voltage high frequency switching power supply. The ac input voltage is $220 \mathrm{~V} 50 \mathrm{~Hz}$ supplied to rectifier circuit in order to produce the dc voltage of $310 \mathrm{~V}$. From the dc voltage to ac voltage, the inverter controlled by Pulse Width Modulation (PWM) is used to obtain the high frequency of $25 \mathrm{kHz}$. The low voltage of inverter from the primary side steps up to high voltage of the secondary side at $3 \mathrm{kV}$ in order to produce the High Frequency High Voltage (HF-HV) into the ozone tube. Then, it generates the ozone gas by applied thermoelectric for produces cool air of temperature decreasing in ozone tube. 


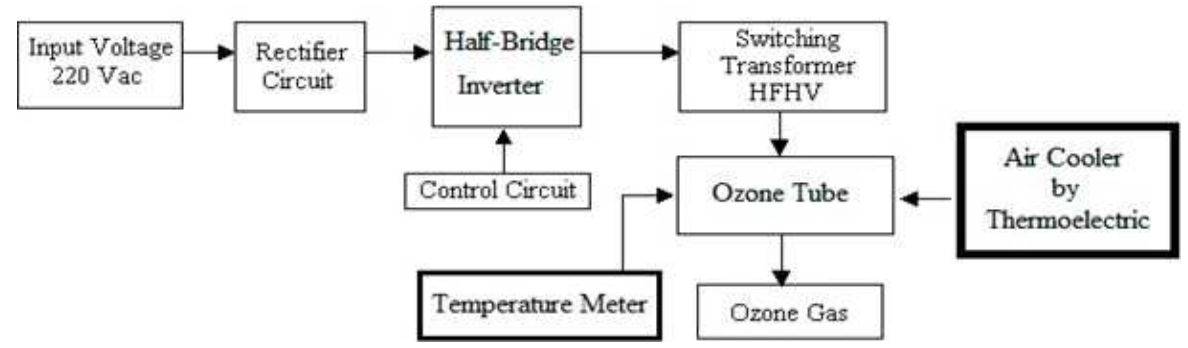

Figure 1. Block diagram of ozonizer using cool air production system.

\subsection{Part of Ozonizer}

\subsubsection{Design of Ozone Tube}

The principle of ozone tube designing is the ozone gas quantity will occur well under unsmooth electric field. Therefore, two-layer electric insulator is chosen for the ozone tube design as the difference permittivity $(\varepsilon)$ of the electric insulator. It is suitable for non-uniform electric field to have the nearly $\varepsilon$ of each layer in electric field stress. Therefore, two-layer co-core of cylinder ozone tube design is chosen under the followings as shown in Figure 2.

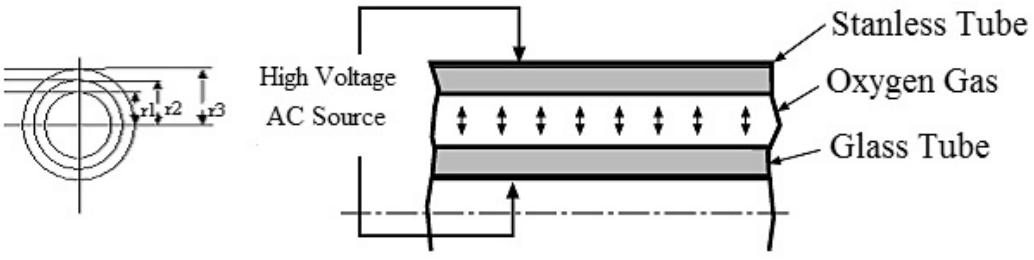

Figure 2. The structure of ozone tube.

Energy per volume $\mathrm{W}=\frac{1}{2} \int_{\mathrm{Vol}} \varepsilon \mathrm{E}^{2} \mathrm{dv}$

From equation (1), $E_{\min }$ and $E_{\max }$ are given by $E=\sqrt{\frac{2 \times W_{\min }}{\varepsilon \text { vol }}}$

The voltage $\left(\mathrm{V}_{\min }\right.$ and $\left.\mathrm{V}_{\max }\right)$ of ozone tube is given in equation (2)

$$
\mathrm{V}=\frac{\mathrm{E} \cdot \mathrm{r}_{2} \cdot \varepsilon_{2}\left(\varepsilon_{1} \ln \left(\frac{\mathrm{r}_{3}}{\mathrm{r}_{2}}\right)+\varepsilon_{2} \ln \left(\frac{\mathrm{r}_{2}}{\mathrm{r}_{1}}\right)\right)}{\varepsilon_{1} \times \varepsilon_{2}}
$$

Where $\mathrm{V}_{\min }$ and $\mathrm{V}_{\max }$ are the minimum and maximum voltage of the ozone tube set in order to produce ozone gas, respectively.

\subsubsection{The HF-HV Switching Power Supply for Ozone Tube}

The HF-HV AC switching power supply is controlled by IC\#TL494 [6] as shown in Figure 3 Switching devices, Power MOSFETs, are used in the half-bridge inverter controlled by the PWM strategy from IC\#TL494. The switching frequency is $25 \mathrm{kHz}$. The energy from inverter can transfer through a HF-HV transformer to produce HF-HV AC supplying $3 \mathrm{kV}$ for the ozone tube. This AC supply is shown in Figure 3.

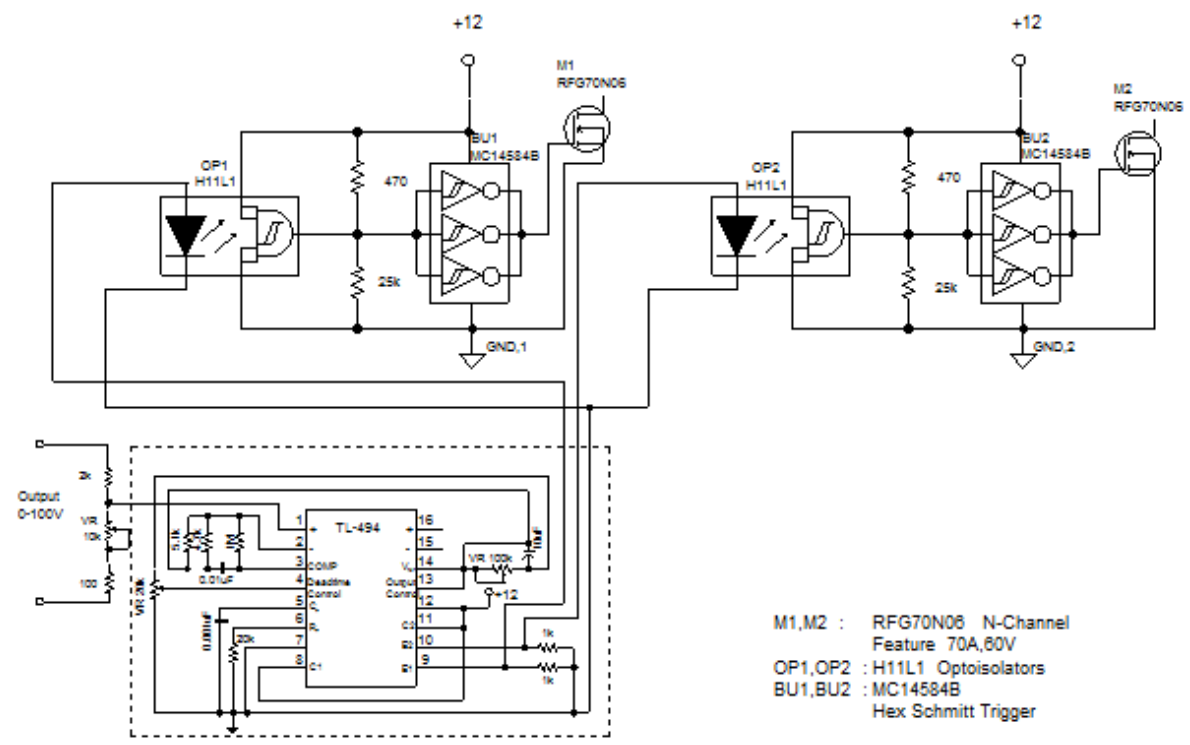

Figure 3. $H F-H V$ switching power supply circuit using half-bridge inverter. 


\subsection{Part of Cool Air Production System from Thermoelectric}

\subsubsection{Principle of Thermoelectric Cooling}

Thermoelectric cooling uses the Peltier effect to create a heat flux between the junction of two different types of materials. A Peltier cooler, heater, or thermoelectric heat pump is a solid-state active heat pump which transfers heat from one side of the device to the other, with consumption of electrical energy, depending on the direction of the current. Such an instrument is also called a Peltier device, Peltier heat pump, solid state refrigerator, or thermoelectric cooler (TEC). They can be used either for heating or for cooling (refrigeration), although in practice the main application is cooling. It can also be used as a temperature controller that either heats or cools [5] shown in Figure 4.

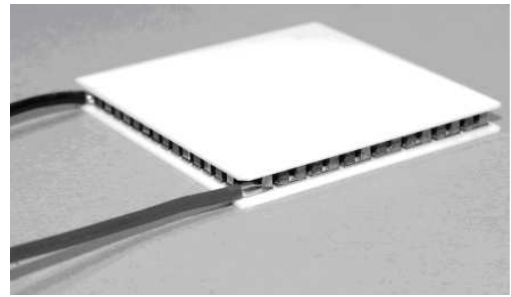

Figure 4. Thermoelectric /Peltier cooling $\left(12 V_{d c} 40 \mathrm{~W}\right)$.
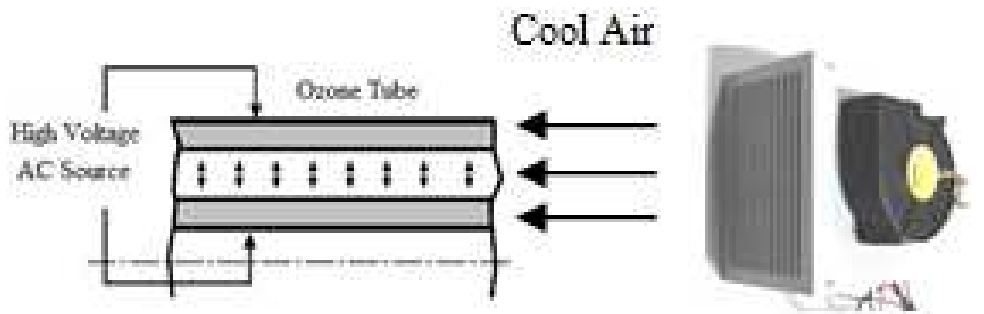

Figure 6. The connecting of ozone tube and Cool air production system by applied thermoelectric.

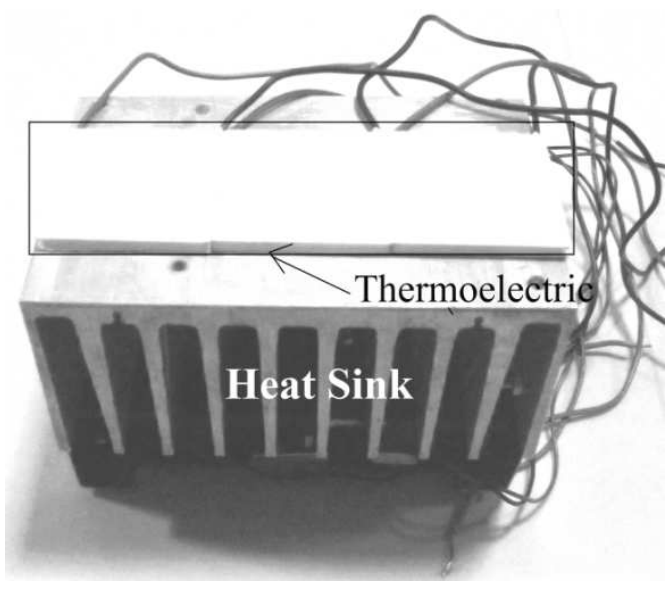

Figure 7. Cool air production system from thermoelectric.

\subsection{Results of Electrical Parameter of DC Power Supply}

The results of measurement of input current signal and input harmonics current signal of DC switching power supply $12 \mathrm{~V} 100 \mathrm{~A}$ of cool air production system from thermoelectric

\subsubsection{Switching Power Supply 12V 100A}

The system specifications are as follows

Rated load VA rating $=1.2 \mathrm{kVA}$

Rated load voltage $=12 \mathrm{~V}$

Rated load current $=100 \mathrm{~A}$

Rated dc link voltage $=310 \mathrm{~V}$

AC main supply $=220 \mathrm{~V} 50 \mathrm{~Hz} 1$ phase

\section{Results and Discussion}

The experiment results of the first part are input current signal and input harmonics current signal of Direct Current (DC) switching power supply $12 \mathrm{~V} 100 \mathrm{~A}$ for thermoelectric shown in Figure 8 In second part are the results of the used power, temperature of ozone tube and ozone gas quantity of ozonizer shown in table 1.

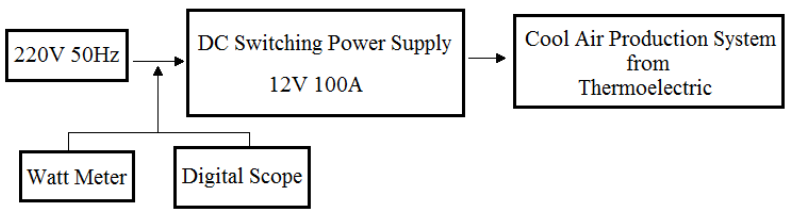

Figure 5. Diagram block for results measurement of electrical. shown in Figure 8.

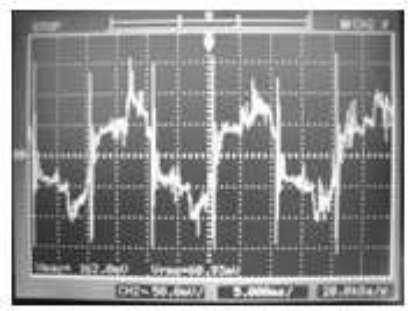

(a)

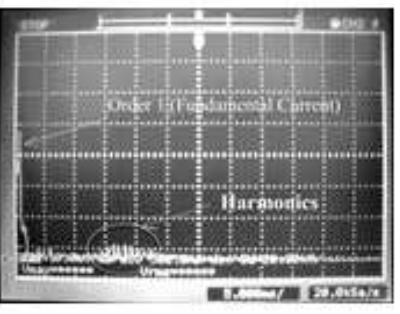

(b)
Figure 8. (a) Input current signal and (b) Input harmonics current of DC switching power supply $12 \mathrm{~V} 100 \mathrm{~A}$ of cool air production system from thermoelectric.

\subsection{Results of the Power, Temperature Measurement of Ozone Tube}

The results of the power, temperature measurement and ozone gas quantity of ozone tube shown in table 1 . 
Table 1. The result of the power, temperature of ozone tube and ozone gas quantity of ozonizer.

\begin{tabular}{lll}
\hline Power(kW) & Temperature $\left({ }^{\circ} \mathbf{C}\right)$ & Ozone gas quantity $\left(\mathrm{mgO}_{3} / \mathbf{h r}\right)$ \\
\hline 0.3 & 29 & 216.8 \\
0.3 & 25 & 397.5 \\
\hline
\end{tabular}

\section{Conclusion}

To test the temperature of the ozone tube in ozonizer by the application of cold air produced from thermoelectric. It is found that when used in the production of ozone gas from ozone tube, the measured temperature is equal to $29^{\circ} \mathrm{C}$, the amount of ozone gas that is equal to $216.8 \mathrm{mgO}_{3} / \mathrm{hr}$ and production of harmonics quantity of input current as shown in Figure 8 (b) But by the cold air production from thermoelectric blowing into the ozone tube, it is found that the temperature will drop to $25^{\circ} \mathrm{C}$, but the amount of ozone gas will increase as $379.5 \mathrm{mgO}_{3} / \mathrm{hr}$ by maintaining the power at 0.3 kilo-watt. It is concluded that while cold air production of thermoelectric reduces the temperature, and it can help to increase the amount of ozone gas because when the temperature drops, the decomposition of ozone gas is less. In the future, researcher will increase the amount of ozone gas to be used to solve environmental problems in various industries as well as to find ways to reduce the harmonics quantity for less in order to maintain the stability of the electrical system to be better.

\section{References}

[1] S. Ketkaew, "The study of ozone gas generating technique using high frequency, high voltage dc switching power supply of high ripple voltage", Journal of King Mongkut's Institute of Technology Ladkrabang, 2005, Vol. 22, No. 2, pp. 1-6.

[2] P. Rattanawichain, "Ozone generator for solar energy", Master Thesis in Department of Electrical Engineering, Faculty of Engineering, King Mongkut's Institute of Technology Ladkrabang, Thailand, 2002.
[3] S. Ketkaew, "Air cleaner by using high voltage electrostatic," Proceeding of the IEEE International Conference on Power System Technology, China, 2002, pp. 1611-1614.

[4] TL494 Data sheet, Pulse-width- modulation control circuits, Texas instruments, 2002, pp. 1-10.

[5] http://en.wikipedia.org/wiki/Thermoelectric_cooling

[6] Suwat Dun, Technique \& Design of Switching Power Supply, Intelthai.

[7] Siseerot Ketkaew, The Case Study of $5 \mathrm{kHz}-25 \mathrm{kHz}$ High Frequency Adjustment in Converter Circuit to Generate Ozone Gas, AU Journal of Technology, Volume 11, Number 1, July 2007.

[8] S. Ketkaew, 2012, "Plasma Ozonizer Using Micro-Converter for Ammonia $\left(\mathrm{NH}_{3}\right)$ Decreasing in Shrimp Food Production", Procedia Engineering 32, 2012, 148-154.

[9] C., G., High-Frequency Switching Power Supplies- Theory and Design, New York, McGraw - Hill, 1989.

[10] S. Ketkaew, Air cleaner by using high voltage electrostatic, Proceeding of the IEEE International Conference on Power System Technology, China, 2002, pp. 1611-1614.

[11] Sabert Oglesby Jr. et al, A Manual of Electrostatic Precipitator Teachnology, Soutern Research Institute Birmingham, Alabama, 1976.

[12] S. Ketkaew and A. Jangwanitlert. 2007. A Study of Switching Frequency Changingin Full Bridge Inverter of Ozone Gas Generating Quantity. Proceeding of the fourth International Power Conversion Conference, Nagoya Japan. 162-166.

[13] J. Marcos Alonso, Jesus Cardesín, Emilio Lopez Corominas, Manuel Rico-Secades and Jorge García. 2004. Low-Power High-Voltage High-Frequency Power Supply for Ozone Generation, IEEE Transactions on Industry Applications. 40(2).

[14] G., K. D. 1989. Power Semiconductor Controller Drive, Prentice - Hall. 